\title{
Quantification of Artificial Surfaces Impact on Urban Heat Island of Novi Sad (Vojvodina, Serbia)
}

\author{
Marković Vladimir ${ }^{A^{*}}$, Savić Stevan ${ }^{\mathrm{B}}$, Arsenović DanielaA, Stankov Uglješa ${ }^{\mathrm{A}}$, Dolinaj Dragan ${ }^{\mathrm{B}}$ \\ Received: September 2013 | Revised: September 2013 | Accepted: September 2013
}

\begin{abstract}
Within urban zones land cover, being the expression of human activities, could be greatly modificated by changes in urban surfaces. Land cover modifications can be measured with mathematical metrics that quantify different aspects of landscape pattern. This research examines land cover patches by a set of landscape metrics for area and size. (Number of patches - NP, CA - Class area, Mean patch size - MPS, \% - class ratio). The classification of land cover patches was based on Corine Land Cover 2006 (CLC2006) seamless vector data. The main goal of the research is to investigate the impact of artificial surfaces on Urban Heat Island (UHI) in the City of Novi Sad. The methodology is based on crossing of landscape and geographical approach to UHI research. UHI metrics of Novi Sad reveal strong human impact indicating direct proportional relation between presence of artificial surface areas and increased air temperatures.
\end{abstract}

Key words: Corine Land Cover, Urban Heat Island, GIS, Novi Sad, Serbia

\section{Introduction}

It is crucial in land cover and climate change research to systematically describe the environment in order to detect its changes, human-related causes and responses. Earth's land surface and its changes are central in most of the biophysical processes of global environmental change. Therefore, land change is qualified as a forcing function within the global environmental change (Grugia et al., 2010, Jansen and Di Gregorio, 2002; Turner, 2002; Turner, 2006).

Land cover has been defined by the attributes of the Earth's land surface and immediate subsurface, including biota, soil, topography, surface and groundwater, and human (mainly built-up) structure (Lambin et al., 2006).

This paper analyse land cover patches and urban temperature intensity of the City of Novi Sad (Vojvo- dina, Serbia). The main purpose of the analyses is to quantify land cover patches within zones of annual mean urban heat island (UHI) temperature intensity of Novi Sad. Quantified land cover patches are bringing most useful information about state of UHI that is impacted by human influences.

\section{Materials and methods}

According to Oke (1984) and Svensson et al. (2002) three types of models can be applied for climate related research in urban environments: numerical, physical and empirically based models.

For input model, authors were used model of annual mean UHI intensity created by Unger et al. (2011a; 2011b), that is based on empirical modeling study of Balázs et al. (2009). Statistical calculations were done

\footnotetext{
A Center for Spatial Information of Vojvodina Province, Faculty of Science, University of Novi Sad; Trg Dositeja Obradovića 3, 21000 Novi Sad, Serbia

B Climatology and Hydrology Research Centre, Faculty of Science, University of Novi Sad; Trg Dositeja Obradovića 3, 21000 Novi Sad, Serbia

* Corresponding author: Vladimir Marković, e-mail: vladimir.markovic@dgt.uns.ac.rs
} 
using ArcGIS 9.3 software. Quantification of landscape elements (land cover patches) in this papers were based on following landscape metrics:

- NP (Number of patches) - equals the number of land cover patches in each patch type - class.

- CA (Class area) - equals the sum of the areas belonging to a given class. Units of equals: quadrate meters $\left(\mathrm{m}^{2}\right)$.

- MPS (Mean patch size) - equals the sums of the area of all land cover patches divided by the number of patches of the same type. Units of equals: quadrate meters ( $\mathrm{m} 2$ ).

- \% (Percentage) - represent ratio of each land cover class.

The classification of land cover patches was based on Corine Land Cover 2006 (CLC2006), that provides consistent information on land cover and land cover changes across Europe.

CLC classification consists of 44 land cover categories. The five general levels are: 1 ) artificial surfaces, 2) agricultural areas, 3) forests and semi-natural areas, 4) wetlands, and 5) water bodies (Heymann et al., 1994).

Land cover patches - class types that are represented in investigated area are following:

112 Artificial surfaces. Urban fabric. Discontinuous urban fabric

121 Artificial surfaces. Industrial, commercial and transport units. Industrial or commercial units

122 Artificial surfaces. Industrial, commercial and transport units. Road and rail networks and associated land

123 Artificial surfaces. Industrial, commercial and transport units. Port areas

141 Artificial surfaces. Artificial, non-agricultural vegetated areas. Green urban areas

142 Artificial surfaces. Artificial, non-agricultural vegetated areas. Sport and leisure facilities

211 Agricultural areas. Arable land. Non-irrigated arable land

231 Agricultural areas. Pastures

242 Agricultural areas. Heterogeneous agricultural areas. Complex cultivation patterns

243 Agricultural areas. Heterogeneous agricultural areas. Land principally occupied by agriculture, with significant areas of natural vegetation

311 Forest and semi natural areas. Forests. Broadleaved forest

321 Forest and semi natural areas. Scrub and/or herbaceous vegetation associations. Natural grassland

324 Forest and semi natural areas. Scrub and/or herbaceous vegetation associations. Transitional woodland-shrub

331 Forest and semi natural areas. Open spaces with little or no vegetation. Beaches, dunes, sands
411 Wetlands. Inland wetlands. Inland marshes

511 Water bodies. Inland waters. Water courses

512 Water bodies. Inland waters. Water bodies

\section{Study area}

Novi Sad is located in the northern part of Serbia (Vojvodina Province) ( $\left.45^{\circ} 15^{\prime} \mathrm{N}, 19^{\circ} 50^{\prime} \mathrm{E}\right)$. The investigated area is plain (mostly from 80 to $86 \mathrm{~m}$ a.s.l.) on Holocene sediments with a gentle relief, so generally, the climate is free from orographic effects (Unger et al. 2011a; 2011b).

According to Koppen-Geiger climate classification, the region around Novi Sad is categorised as Cf climate (temperate warm climate with a rather uniform annual distribution of precipitation) (Kottek et al., 2006). In Novi Sad, the annual mean air temperature is $11.1^{\circ} \mathrm{C}$ with an annual range of $22.1^{\circ} \mathrm{C}$. The mean annual precipitation amount is $615 \mathrm{~mm}$ (based on data from 1949 to 2008). Novi Sad is the second largest city in Serbia and has a population of 285.756 inhabitants (data from 2009) in a built-up area of approximately $60 \mathrm{~km}^{2}$ (Savić et al. 2013).

\section{Results and discussion}

Based on previous research of Unger et al. (2011a, 2011b) and Popov and Savic (2010) there are nine different zones of annual mean UHI temperature intensity in area of Novi Sad $\left(0^{\circ} \mathrm{C},+0.5^{\circ} \mathrm{C},+1^{\circ} \mathrm{C},+1.5^{\circ} \mathrm{C},+2^{\circ} \mathrm{C},+2.5^{\circ} \mathrm{C},+3^{\circ} \mathrm{C}\right.$, $+3.5^{\circ} \mathrm{C}$ and $+4^{\circ} \mathrm{C}$ ). Evaluation of zones is based on quantification of land cover patches in each zone, and this research is focused on the comparison of artificial surface impacts on each. The main result is land cover patches analyse with highlight on artificial surfaces impact on increasing temperatures in Novi Sad (Figure 1).

The zone of $0^{\circ} \mathrm{C}$ of UHI intensity occupies 37.11ha, and it is $0.64 \%$ of the total urban area (Table 1 ). This is external zone and the smallest one, with climate conditions the most likely as rural area in Novi Sad surroundings.

Number of patches (NP) in $0^{\circ} \mathrm{C}$ zone is 7 . That is $3.78 \%$ from all patches in research area. That means this zone is moderate fragmented compared with other zones. Total area of artificial surfaces $(112,121,141)$ encompass $36.12 \%$ of $\mathrm{o}^{\circ} \mathrm{C}$ zone.

The area of $0.5^{\circ} \mathrm{C}$ zone occupies $661.4 \mathrm{oha}$, that is $11.35 \%$ of the total urban area (Table 2).

$\mathrm{NP}$ in $0.5^{\circ} \mathrm{C}$ zone is 43 . That is $23.24 \%$ from all patches in research area. That means this zone is extensively fragmented compared with other zones. Total area of artificial surfaces $(112,121,141,142,122)$ encompass $26.76 \%$. Even this is smaller than in the $0^{\circ} \mathrm{C}$ zone, the impact of artificial surface is more evidence because there are five artificial surfaces patches. 


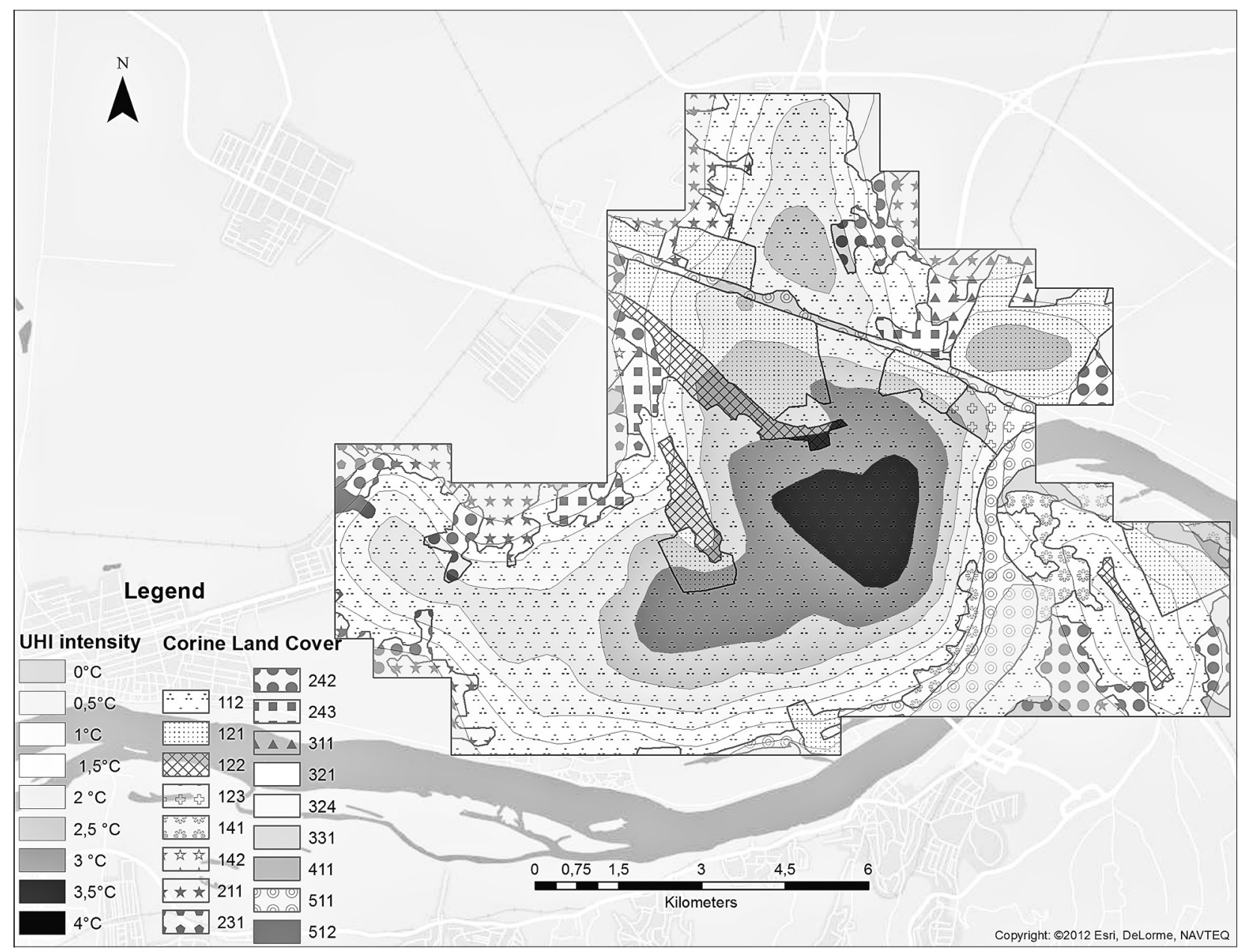

Figure 1. Annual mean UHI temperature intensity and CLC of Novi Sad

Table $1.0^{\circ} \mathrm{C}$ zone of UHI temperature intensity

\begin{tabular}{|c|c|r|r|r|}
\hline Class & NP & \multicolumn{1}{c|}{ CA } & \multicolumn{1}{c|}{ MPS } & \multicolumn{1}{c|}{$\%$} \\
\hline 242 & 1 & 126024.85 & 126024.85 & 33.96 \\
\hline 141 & 1 & 103175.8 & 103175.8 & 27.80 \\
\hline 411 & 1 & 66977.68 & 66977.68 & 18.05 \\
\hline 112 & 1 & 27055.28 & 27055.28 & 7.29 \\
\hline 311 & 1 & 24704.33 & 24704.33 & 6.66 \\
\hline 511 & 1 & 19380.59 & 19380.59 & 5.22 \\
\hline 121 & 1 & 3805.73 & 3805.73 & 1.03 \\
\hline
\end{tabular}

Note: NP - number of patches; CA - class area; MPS - mean patch size

The area of $1^{\circ} \mathrm{C}$ zone occupies $975.4 \mathrm{oha}$, that is $16.74 \%$ of the total urban area (Table 3 ).

$\mathrm{NP}$ in $1^{\circ} \mathrm{C}$ zone is 44 . That is $23.78 \%$ from all patches in research area. That means this zone is extensively fragmented compared with other zones. Total area of artificial surfaces $(112,121,141,142,122,123)$ encompass $54.36 \%$. Comparing with previous zone, percentage of area under the artificial surfaces is higher for $27.6 \%$ and temperature is higher for $0.5{ }^{\circ} \mathrm{C}$.

The area of $1.5^{\circ} \mathrm{C}$ zone occupies 886.83 ha, that is $15.22 \%$ of the total area (Table 4 ).
Table $2.0 .5^{\circ} \mathrm{C}$ zone of UHI temperature intensity

\begin{tabular}{|c|c|r|r|r|}
\hline Class & NP & \multicolumn{1}{c|}{ CA } & \multicolumn{1}{c|}{ MPS } & \multicolumn{1}{c|}{$\%$} \\
\hline 211 & 6 & 1708140.8 & 284690.14 & 25.83 \\
\hline 511 & 1 & 1022749.9 & 1022749.9 & 15.45 \\
\hline 242 & 7 & 957568.77 & 136795.54 & 14.48 \\
\hline 112 & 4 & 855701.29 & 213925.32 & 12.94 \\
\hline 121 & 5 & 524174.95 & 104834.99 & 7.93 \\
\hline 311 & 3 & 326947.66 & 108982.55 & 4.94 \\
\hline 141 & 2 & 280863.46 & 140431.73 & 4.25 \\
\hline 231 & 4 & 275651.18 & 68912.79 & 4.17 \\
\hline 411 & 3 & 234983.99 & 78328 & 3.55 \\
\hline 324 & 2 & 164723.08 & 82361.54 & 2.49 \\
\hline 243 & 2 & 83360.43 & 41680.21 & 1.26 \\
\hline 142 & 1 & 77541.13 & 77541.13 & 1.17 \\
\hline 331 & 1 & 70257.25 & 70257.25 & 1.06 \\
\hline 122 & 1 & 31345.77 & 31345.77 & 0.47 \\
\hline 512 & 1 & 69.98 & 69.98 & 0.01 \\
\hline
\end{tabular}

NP in $1.5^{\circ} \mathrm{C}$ zone is 36 . That is $19.46 \%$ from all patches in research area. That means this zone is extensively fragmented compared with other zones. Total area of artificial surfaces $(112,121,141,122,123)$ encompass 
Table $3.1^{\circ} \mathrm{C}$ zone of UHI temperature intensity

\begin{tabular}{|c|r|r|r|r|}
\hline Class & NP & \multicolumn{1}{c|}{ CA } & \multicolumn{1}{c|}{ MPS } & \multicolumn{1}{c|}{$\%$} \\
\hline 112 & 4 & 3254138.6 & 813534.64 & 33.36 \\
\hline 242 & 8 & 1281730.7 & 160216.34 & 13.14 \\
\hline 121 & 6 & 1200064.5 & 200010.75 & 12.30 \\
\hline 211 & 6 & 932607.46 & 155434.58 & 9.56 \\
\hline 511 & 1 & 846785.85 & 846785.85 & 8.68 \\
\hline 141 & 3 & 679486.74 & 226495.58 & 6.95 \\
\hline 243 & 3 & 462332.95 & 154110.98 & 4.73 \\
\hline 311 & 1 & 309672.83 & 309672.83 & 3.17 \\
\hline 324 & 3 & 299679.5 & 99893.17 & 3.07 \\
\hline 231 & 2 & 134407.61 & 67203.8 & 1.37 \\
\hline 331 & 1 & 115805.73 & 115805.73 & 1.18 \\
\hline 142 & 1 & 92225.77 & 92225.77 & 0.94 \\
\hline 122 & 1 & 65718.91 & 65718.91 & 0.67 \\
\hline 512 & 1 & 56744.23 & 56744.23 & 0.58 \\
\hline 411 & 1 & 12258.66 & 12258.66 & 0.12 \\
\hline 123 & 1 & 10003.53 & 10003.53 & 0.10 \\
\hline 321 & 1 & 355.64 & 355.64 & 0.01 \\
\hline & & & & \\
\hline
\end{tabular}

$77.47 \%$ of $1.5^{\circ} \mathrm{C}$ zone. Comparing with previous zone, percentage of area under the artificial surfaces is higher for $23.11 \%$.

The area of $2^{\circ} \mathrm{C}$ zone occupies 852.28 ha, that is $14.63 \%$ of the total urban area (Table 5 ).

$\mathrm{NP}$ in $2{ }^{\circ} \mathrm{C}$ UHI zone is 27 . That is $14.59 \%$ from all patches in research area. That means this zone is moderate fragmented compared with other zones. Total area of artificial surfaces $(112,121,122,123,141)$ encompass $90.95 \%$ of the zone. Comparing with previous zone, percentage of area under the artificial surfaces is higher for $13.48 \%$.

The area of $2.5^{\circ} \mathrm{C}$ zone occupies 914.34ha (Table 6), that is $15.69 \%$ of the total area.

Table $4.1 .5^{\circ} \mathrm{C}$ zone of UHI temperature intensity

\begin{tabular}{|c|c|r|r|r|}
\hline Class & NP & \multicolumn{1}{c|}{ CA } & \multicolumn{1}{c|}{ MPS } & \multicolumn{1}{c|}{$\%$} \\
\hline 112 & 4 & 5136849.8 & 1284212.5 & 57.92 \\
\hline 121 & 5 & 908205.43 & 181641.09 & 10.24 \\
\hline 242 & 7 & 458564.38 & 65509.2 & 5.17 \\
\hline 243 & 3 & 431331.52 & 143777.17 & 4.86 \\
\hline 511 & 1 & 425861.95 & 425861.95 & 4.80 \\
\hline 141 & 2 & 356923.56 & 178461.78 & 4.02 \\
\hline 122 & 3 & 352700.77 & 117566.92 & 3.98 \\
\hline 324 & 2 & 274137.01 & 137068.51 & 3.09 \\
\hline 211 & 4 & 232541.76 & 58135.44 & 2.62 \\
\hline 311 & 1 & 134573.62 & 134573.62 & 1.52 \\
\hline 123 & 1 & 115902.5 & 115902.5 & 1.31 \\
\hline 512 & 1 & 29638.4 & 29638.4 & 0.33 \\
\hline 331 & 1 & 9504.73 & 9504.73 & 0.11 \\
\hline 231 & 1 & 1660.8 & 1660.8 & 0.02 \\
\hline
\end{tabular}

Table $5.2^{\circ} \mathrm{C}$ zone of UHI temperature intensity

\begin{tabular}{|c|c|r|r|r|}
\hline Class & NP & \multicolumn{1}{c|}{ CA } & \multicolumn{1}{c|}{ MPS } & \multicolumn{1}{c|}{$\%$} \\
\hline 112 & 3 & 5724945.7 & 1908315.2 & 67.17 \\
\hline 121 & 5 & 1452142.7 & 290428.54 & 17.04 \\
\hline 122 & 3 & 345689.88 & 115229.96 & 4.06 \\
\hline 511 & 1 & 329673.8 & 329673.8 & 3.87 \\
\hline 242 & 4 & 240835.79 & 60208.95 & 2.83 \\
\hline 123 & 1 & 167078.69 & 167078.69 & 1.96 \\
\hline 243 & 3 & 97675.33 & 32558.44 & 1.15 \\
\hline 141 & 1 & 61789.41 & 61789.41 & 0.72 \\
\hline 324 & 2 & 39381.42 & 19690.71 & 0.46 \\
\hline 211 & 2 & 32768.74 & 16384.37 & 0.38 \\
\hline 512 & 1 & 23284.04 & 23284.04 & 0.27 \\
\hline 311 & 1 & 7536.59 & 7536.59 & 0.09 \\
\hline
\end{tabular}

$\mathrm{NP}$ in $2.5^{\circ} \mathrm{C}$ zone is 12 . That is $6.49 \%$ from all patches in research area. That means this zone is less fragmented compared with other zones. Total area of artificial surfaces $(112,121,122,123)$ encompass $96.06 \%$ of the zone. Comparing with previous zone, percentage of area under the artificial surfaces is higher for $5.11 \%$.

Table $6.2 .5^{\circ} \mathrm{C}$ zone of UHI temperature intensity

\begin{tabular}{|c|c|r|r|r|}
\hline Class & NP & \multicolumn{1}{c|}{ CA } & \multicolumn{1}{c|}{ MPS } & \multicolumn{1}{c|}{$\%$} \\
\hline 112 & 2 & 6944938.1 & 3472469.1 & 75.96 \\
\hline 121 & 4 & 1265686.3 & 316421.59 & 13.84 \\
\hline 122 & 2 & 396237.23 & 198118.62 & 4.33 \\
\hline 511 & 1 & 250420.89 & 250420.89 & 2.74 \\
\hline 123 & 1 & 176351.99 & 176351.99 & 1.93 \\
\hline 242 & 2 & 109816.23 & 54908.11 & 1.20 \\
\hline
\end{tabular}

The area of $3^{\circ} \mathrm{C}$ zone occupies $705.82 \mathrm{ha}$, that is $\mathbf{1 2 . 1 1 \%}$ of the total urban area (Table 7).

$\mathrm{NP}$ in $3^{\circ} \mathrm{C}$ zone is 10 . That is $5.41 \%$ from all patches in research area. That means this zone is less fragmented compared with other zones. Total area of artificial surfaces $(112,121,122,123)$ encompass $99.98 \%$. Comparing with previous zone, percentage of area under the artificial surfaces is higher for $3.92 \%$ and temperature is higher for $0.5^{\circ} \mathrm{C}$.

The area of $3.5^{\circ} \mathrm{C}$ zone occupies 586.71 ha, that is $10.07 \%$ of the total area (Table 8 ).

$\mathrm{NP}$ in $3.5^{\circ} \mathrm{C}$ zone is 5 . That is $2.70 \%$ from all patches in research area. That means this zone is less fragmented compared with other zones. Total area of ar-

Table $7.3^{\circ} \mathrm{C}$ zone of UHI temperature intensity

\begin{tabular}{|c|c|r|r|r|}
\hline Class & NP & \multicolumn{1}{c|}{ CA } & \multicolumn{1}{c|}{ MPS } & \multicolumn{1}{c|}{$\%$} \\
\hline 112 & 2 & 4667418.9 & 2333709.5 & 66.13 \\
\hline 121 & 4 & 1877349 & 469337.26 & 26.60 \\
\hline 122 & 2 & 484992.93 & 242496.46 & 6.87 \\
\hline 123 & 1 & 27254.58 & 27254.58 & 0.39 \\
\hline 511 & 1 & 1184.55 & 1184.55 & 0.02 \\
\hline
\end{tabular}


Table $8.3 .5^{\circ} \mathrm{C}$ zone of UHI temperature intensity

\begin{tabular}{|c|c|r|r|r|}
\hline Class & NP & \multicolumn{1}{c|}{ CA } & \multicolumn{1}{c|}{ MPS } & \multicolumn{1}{c|}{$\%$} \\
\hline 112 & 1 & 5539619.8 & 5539619.8 & 94.42 \\
\hline 121 & 3 & 249244.87 & 83081.62 & 4.25 \\
\hline 122 & 1 & 78329.8 & 78329.8 & 1.34 \\
\hline
\end{tabular}

tificial surfaces $(112,121,122)$ encompass $100 \%$ of the zone. Comparing with previous zone, percentage of area under the artificial surfaces is higher for $0.02 \%$.

The area of $4^{\circ} \mathrm{C}$ zone occupies 206.19 ha, that is $3.54 \%$ of the total urban area (Table 9).

Table $9.4^{\circ} \mathrm{C}$ zone of UHI temperature intensity

\begin{tabular}{|c|c|c|c|c|}
\hline Class & NP & CA & MPS & $\%$ \\
\hline 112 & 1 & 2061949.7 & 2061949.7 & 100 \\
\hline
\end{tabular}

$\mathrm{NP}$ in $4^{\circ} \mathrm{C}$ zone is 1 . That is $0.54 \%$ from all patches in research area. That means this zone is less fragmented compared with other zones, i.e. this zone is not fragmented at all. Total area of artificial surfaces (112) encompasses $100 \%$. Comparing with previous zone, percentage of area under the artificial surfaces is the same and temperature is higher for $0.5^{\circ} \mathrm{C}$.

\section{Conclusion}

According to the results of the urban heat island pattern in Novi Sad the main conclusions of this study are as follows:

This research examined land cover patches by a set of landscape metrics for area and size and annual mean UHI temperature intensity zones. Evaluation of artificial surface ratio values by temperature zones varies from $26.76 \%$ to $100 \%$ in densely built-up downtown, and temperatures vary from $0^{\circ} \mathrm{C}$ to $+4^{\circ} \mathrm{C}$. The impact of artificial surfaces on increasing temperatures is evident, because in almost all zones (except $0.5^{\circ} \mathrm{C}$ zone), increasing of percentage of area under the artificial surfaces indicates the increasing temperatures in the same area. Results show that total area of temperature zone is opposite proportional with increasing of temperatures, which indicates that artificial surface impact is more effective in smaller zones.

\section{Acknowledgments}

This paper is part of the project No. 114-451-2446 funded by the Provincial Secretariat for Science and Technological Development of the Vojvodina Province, Serbia.

\section{References}

Balázs, B., Unger, J., Gál, T., Sümeghy, Z., Geiger, J., Szegedi, S. 2009. Simulation of the mean urban heat island using $2 \mathrm{D}$ surface parameters: empirical modelling, verification and extension. Meteorological Applications 16, 3, 275- 287.

Grugia, R., Tane, N., Marculescu, A., Padureanu, V. 2010. Modular agriculture - paradigm of globalization dynamics within the context of climatic and scientific changes. Environmental Engineering and Management Journal 9, 1659-1665.

Heymann, Y., Steenmans, Ch., Croissille, G., Bossard, M. 1994. Corine land cover technical guide. EEA, Luxembourg.

Kottek, M., Grieser, J., Beck, C., Rudolf, B., Rubel, F. 2006. World map of the Koppen-Geiger climate classification updated. Meteorologische Zeitschrift 15, 3, 259-263.

Jansen, J.M.L., Di Gregorio, A. 2002. Parametric land cover and land-use classifications as tools for environmental change detection. Agriculture, Ecosystems \& Environment 91, 89-100.

Lambin, E.F., Geist, H.J., Rindfuss, R. R. 2006. Local processes with global impacts. In: Land-use and landcover change: local processes and global impact, Lambin E.F., Geist H. (Eds.), Springer, Berlin, 1-8.

Oke, T.R. 1984. Towards a prescription for the greater use of climatic principles in settlement planning. Energy and Buildings 7, 1-10.

Popov, Z., Savić, S. 2010. The urban climate of Novi Sad. Proceedings of the 2nd Serbian Geographers' Congress-Towards Europe, Novi Sad, Serbia, 10-11 September, Book of Abstract, 62 pp.

Savić, S., Unger, J., Gál, T., Milošević, D., Popov, Z. 2013. Urban heat island research of Novi Sad (Serbia): A review. Geographica Pannonica 17, 1, 32-36.

Svensson, M., Eliasson, I., Holmer, B. 2002. A GIS based empirical model to simulate air temperature variations in the Goteborg urban area during the night. Climate Research 22, 3, 215-226.

Turner, B.L. 2002. Toward integrated land-change science: Advances in 1.5 decades of sustained international research on land-use and land-cover changes. Proc. of the Global Change Open Science Conference, Amsterdam, 21-26.

Turner, B.L. 2006. Land change as a forcing function in global environmental change. In: Our Earth's changing land: an encyclopaedia of land-use and land -cover change, Geist H.J. (Ed.), Greenwood press, London, 25-32.

Unger, J., Savić, S., Gál, T. 2011a. Modelling of the Annual Mean Urban Heat Island Pattern for Planning of Representative Urban Climate Station Network. Advances in Meteorology, vol. 2011, Article ID 398613, 9 pages. doi:10.1155/2011/398613

Unger J., Savić, S., Gál, T. 2011b. Method for representative siting of urban climate station network - Novi Sad (Serbia) as an example. Climate and Constructions - International Conference, October 24-25, 2011, Karlsruhe, Germany, 351-358. 